\title{
Long-Term Survival (>25 Years) of Deceased Donor Kidney Transplant Recipients: A Single-Center Experience
}

\author{
F. Rego ${ }^{a, *}$, P. Alçântara ${ }^{a}$, F. Buinho ${ }^{a}$, A. Gomes da Costa ${ }^{a, b}$, and J. Rodrigues Pena ${ }^{a, c}$

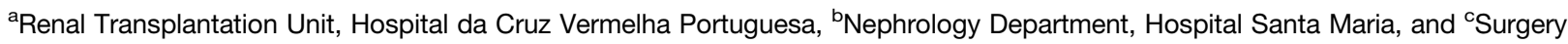 \\ Department, Hospital Curry Cabral, Lisbon, Portugal
}

\begin{abstract}
Introduction. The aim of this preliminary work is to analyze the clinical features of 52 patients with a functional transplanted kidney for $>25$ years (all first transplant and all deceased donor recipients) and to compare with a similar though more complete study from Hôpital Necker-Paris 2012.

Methods. The mean graft survival at 25 years is $12.7 \%$ and at 30 years is $10 \%$. The actual mean serum creatinine concentration is $1.3 \mathrm{mg} / \mathrm{L}$. We analyzed recipient age (mean, 35.9 years) and gender ( 29 men and 23 women). Donor age was $26.7 \pm 10.3$ years. Seven patients $(13.4 \%)$ were transplanted with 1 HLA mismatch, $42.3 \%$ with 2 mismatches, and $44.2 \%$ with 3 mismatches. Mean cold ischemia time was $15.45 \pm 7.7$ hours. Of the recipients, $76 \%$ had immediate graft function; $38 \%$ experienced 1 acute rejection episode and 4 patients had 2 rejection crises. The initial immunosuppressive regimen was azathioprine (AZA) + prednisolone (Pred) in 14 patients, cyclosporin (CSA) + Pred in 13 patients, and CSA + AZA + Pred in 25 patients. Of these patients, $19 \%$ maintained their initial regimen, and 54\% (28 patients) were very stable on a mixed CSA regimen for $>25$ years.
\end{abstract}

Results. We present the major complications (diabetes, neoplasia, and hepatitis $\mathrm{C}$ virus positivity).

Conclusion. Our results in deceased donor kidney recipients for $>25$ years are similar to the mixed population (deceased donors and living donors) presented by the Necker group, although $54 \%$ of our patients remain on CSA immunosuppression, contradicting the idea that its use is not compatible with good long-term kidney function in transplant recipients.

$\mathrm{C}$ ONSIDERABLE progress has been made in the care of transplant recipients regarding organ preservation, quality, and quantity for life of these patients. Mainly, improvements in the management of complications allowed the emergence of a group of long-term survivors who were transplanted several decades ago. These patients constitute a unique population about whom few data have been published. The few publications [1-3] of patients with functioning renal allograft for $>25$ years are usually related to a mixed population of living-related donors (usually the larger percentage) and deceased donor transplant recipients.

Our unit performed our first renal transplantation in June 1980. We celebrated our 500th in 1990 and our 1000th procedure in 1997. We selected a group of patients with functioning kidney graft transplanted $\geq 20$ years ago, all from a deceased donor. The aim of the work was to present and compare the clinical characteristics of this unique population.

\section{PATIENTS AND METHODS}

From July 1980 to January 15, 1994 (20 years ago), we performed 759 transplants; of those recipients, 110 maintain a functioning kidney on follow-up, 52 for $>25$ years and 11 for $>30$ years. The longest surviving recipient has a 33 -year-old, functioning graft. The

*Address correspondence to Fernanda Rego, Unidade de Transplantação Renal, Hospital da Cruz Vermelha Portuguesa, Rua Duarte Galvão, n 54 1549-008 Lisboa, Portugal. E-mail: fewrnandarego@gmail.com

$0041-1345 / 15$ http://dx.doi.org/10.1016/j.transproceed.2015.03.027 


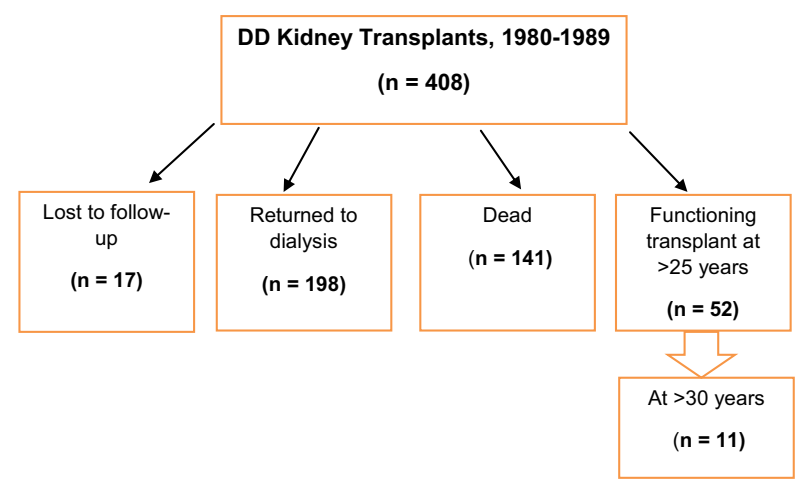

Fig 1. Patient flow of 408 transplant recipients.

52 patients included in the study, were all transplanted and maintained in follow-up in our unit.

Patient data from July 1980 to January 15, 2014, were collected individually patient's medical records and transferred to a database. All patients have a functional first kidney transplant. From 1980 to 15 July 1989, we performed 408 kidney transplants: all ABOcompatible and with negative cross-matching on complementdependent cytotoxicity assays. Of the 408 patients transplanted 25 years ago, 17 were lost to follow-up, 198 returned to dialysis, 141 died, and $52(12.75 \%$ ) are well and stable (Fig 1). Of the 110 patients transplanted through January 1984, 11 (10\%) maintained a graft functioning for $\geq 30$ years. Time from transplant is a minimum of 25 years and a maximum of 33.3 years.

\section{RESULTS}

The donors of the 52 patients were mainly young adults (mean age, $26.7 \pm 10.3$ years). Recipients had a mean age of $35.9 \pm 8.04$ years and their end-stage renal disease was owing to chronic glomerulonephritis $(\mathrm{n}=22)$, hereditary renal disease $(n=4)$, primary urologic disease $(n=5)$, unknown ethology $(\mathrm{n}=11)$, primary immunologic disease $(n=6)$, and chronic pyelonephritis $(n=4)$.

Initial immunosuppression was with antimetabolites and prednisone in 14 patients, cyclosporine and prednisone in 13 patients, and a triple regimen in 25 (Fig 2). Of the patients, $76 \%$ had immediate renal function and $24 \%$ experienced acute tubular necrosis. In $38 \%$ of the patients, there was an episode of acute rejection and 4 patients had 2 episodes. Mean serum creatinine at 1 year posttransplant was $106.08 \pm 30.94 \mathrm{mmol} / \mathrm{L}$. The current creatinine level is $114.923 \pm 61.88 \mathrm{mmol} / \mathrm{L}$ (Fig 3). Table 1 presents the main patient and donor characteristics.

During the follow-up of $\geq 25$ years, 8 patients $(15 \%)$ developed diabetes mellitus. Only 1 patient with diabetes is insulin dependent; there are no major complications and the hemoglobin A1c level is good.

Two patients experienced premature aseptic necrosis of the head of the femur (at 2 and 4 years posttransplant) probably related to high-dose steroids. The older one was 53 years old and treated with methylprednisolone $500 \mathrm{mg} / \mathrm{d}$ for 7 days to treat 2 rejection crises.

Five patients had solid organ cancer: 2 breast, 1 bladder, 1 prostate, and 1 uterus cervix. All these underwent chemotherapy and/or radiotherapy and/or surgery. They lowered the immunosuppression regimen and were switched to mammalian target of rapamycin antagonists (Fig 2). One patient had esophagus lymphoma 8 years posttransplantation. He stopped all the immunosuppression, underwent chemotherapy for 4 months, and his condition improved. He has been without any immunosuppression for 11 years maintaining a normal functioning graft. After all these years, his kidney function began to deteriorate. Four years ago, everolimus $50 \mathrm{mg}$ bid was

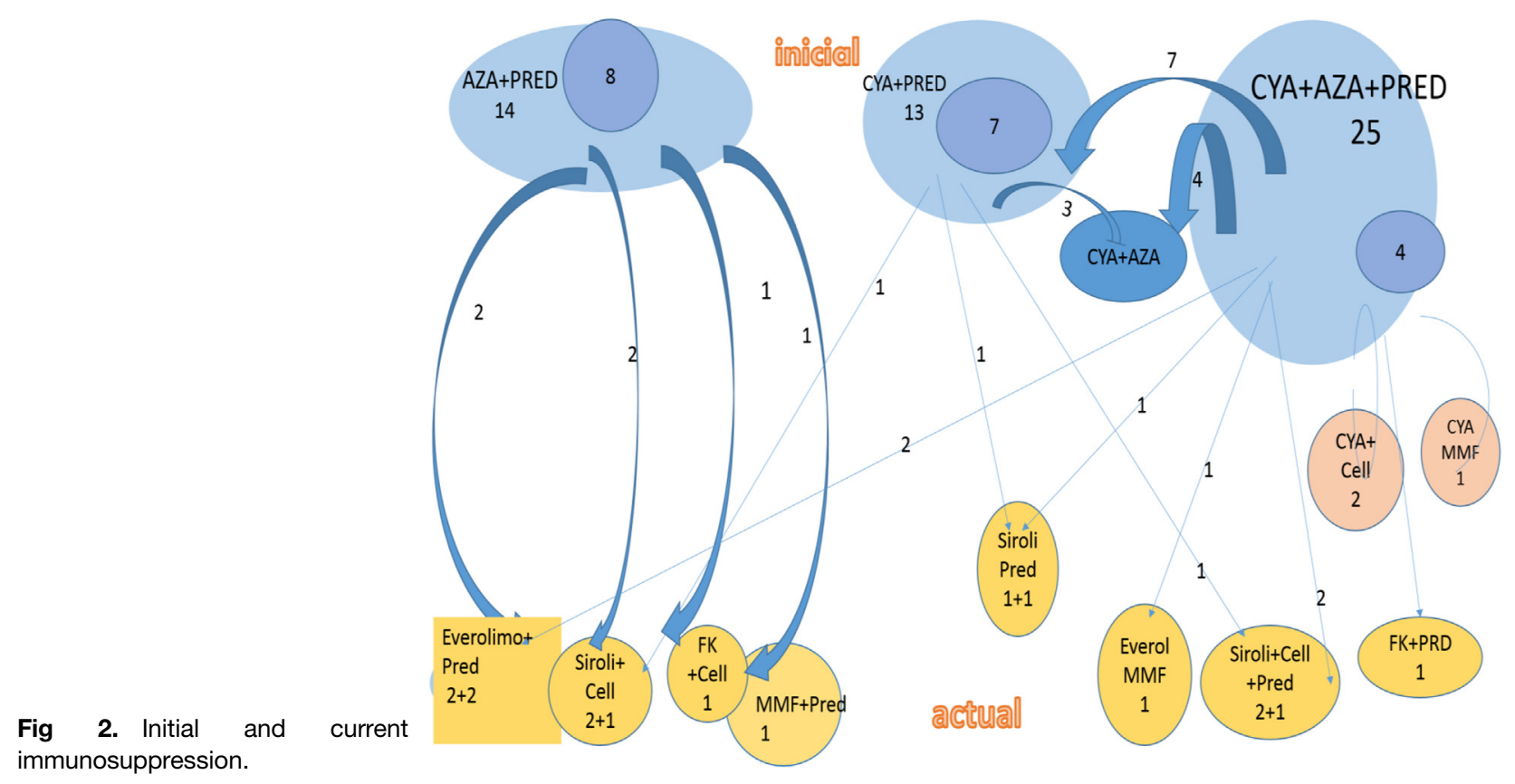




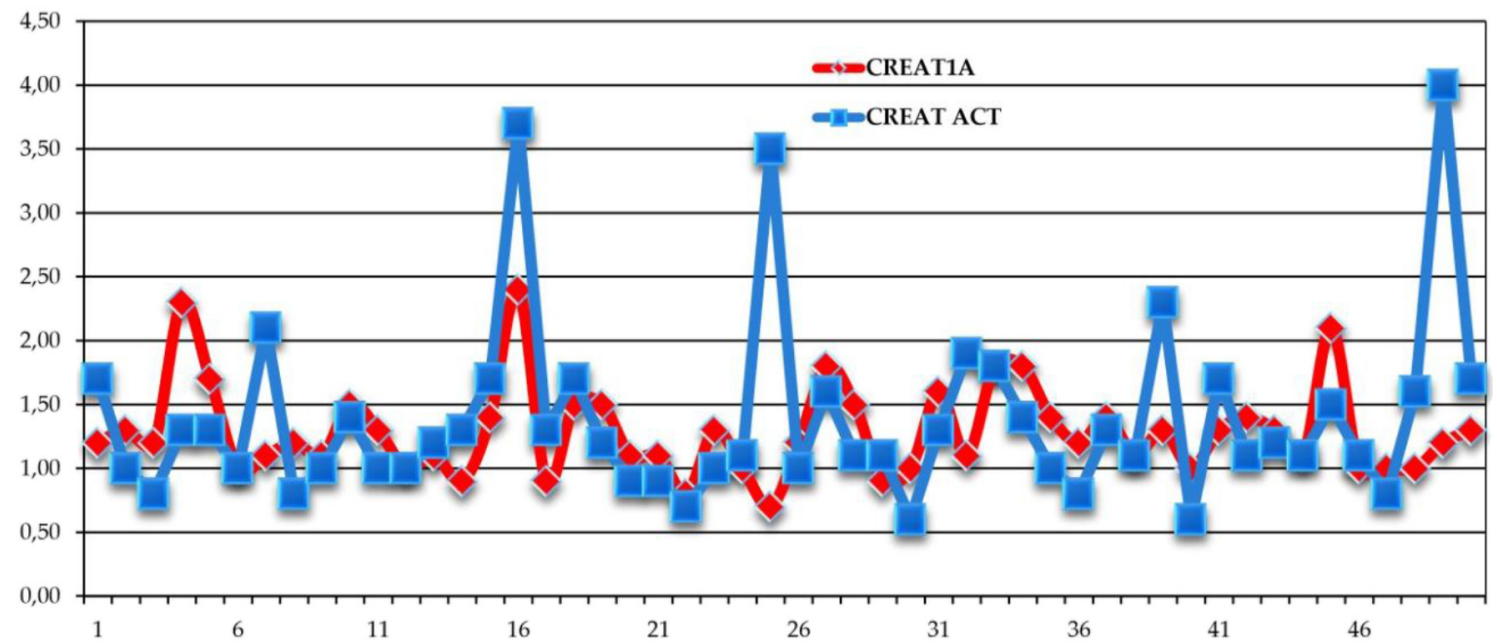

Fig 3. Mean blood creatinine at the first year (red points: $1.28 \pm 0.35 \mathrm{mg} / \mathrm{dL}$ [range, 0.7-2.4]) versus the current year (January 15, 2014 ; blue points: $1.39 \pm 0.6 \mathrm{mg} / \mathrm{dL}$ [range, $0.7-4.0]$ ).

prescribed, and his kidney function returned to normal levels. Three patients had severe skin cancer (all in the azathioprine group), which improved dramatically after changing to mycophenolate mofetil or mammalian target of rapamycin inhibitors. All required surgery and improved afterward. Three patients were positive for hepatitis $\mathrm{C}$ virus at the time of transplantation, but none of them have experienced a major complication to date.

\section{DISCUSSION}

Our report is retrospective, only concerns clinical data, and these are the features we compare with the similar reports in the literature [1-3]. The Hôpital-Necker study [2] analyzed both clinical and immunologic features of very long-term survivors of renal transplant. In our study, only clinical data is available. Even though $44 \%$ of the patients in the Necker study received living donor grafts, a group known for better outcomes, our results on long-term graft survival are similar (10\% vs $11.2 \%)$ at 30 years. Donor age is similar. Cold ischemia time for cadaveric donors is also similar. The etiology of recipient end-stage renal disease is not different, with a predominance of nonprimary immunologic disorders. However, recipient age is higher in our group (35.9 vs 27.1 years in the Necker group) and initial immunosuppression is also different; the Necker data group reviewed data through 1978, whereas we include patients transplanted and treated through 1989. The immunosuppressive regimen at 30 years includes quite a few patients (3\% in Necker group) on calcineurin inhibitors; $54 \%$ of our patients are maintained on a mixed CSA regimen (Figs 2 and 3 ).

The Necker group attributes the good functional results of their patients to the absence of calcineurin inhibitor use, which they believe translated into a prevention of chronic nephrotoxicity. Our results contradict their findings; $54 \%$ of our patients are still on a calcineurin inhibitor-based mixed regimen, in accordance with other studies demonstrating that immune injury is the leading cause of graft damage and loss and that calcineurin inhibitor nephrotoxicity has a minor impact on chronic allograft nephropathy [4-7].

In conclusion, deceased donor transplant recipients can survive with good functional kidneys for a long time $->25$

Table 1. Patient and Allograft Characteristics $(n=52)$

\begin{tabular}{|c|c|}
\hline Characteristic & Value \\
\hline Donor age $(y)$ & $26.7 \pm 10.3$ \\
\hline Recipient age (y) & $35.9 \pm 8.04$ \\
\hline Recipient sex ratio (F/M) & 0.79 \\
\hline Nephrectomy, n (\%) & $2(3.8)$ \\
\hline HLA mismatches (mean) & 2.307 \\
\hline Cold ischemia time $(\mathrm{h})$ & $15.45 \pm 7.7$ \\
\hline \multicolumn{2}{|l|}{ Immunosuppressive regimen (day 1), n (\%) } \\
\hline Antilymphocytes globulins & $2(3.8)$ \\
\hline Azathioprine + prednisone & $14(26.9)$ \\
\hline Cyclosporine + prednisone & $13(25)$ \\
\hline Cyclosporine + azathioprine + prednisone & $25(48)$ \\
\hline \multicolumn{2}{|l|}{ Current immunosuppressive regimen, $\mathrm{n}(\%)$} \\
\hline Azathioprine + prednisone & $8(15.3)$ \\
\hline Cyclosporine + prednisone & $14(26.9)$ \\
\hline Cyclosporine + azathioprine + prednisone & $4(7.7)$ \\
\hline Cyclosporine + azathioprine & $7(21.1)$ \\
\hline Cyclosporine + MMF & $3(5.8)$ \\
\hline Only new immunossupressors & $16(31)$ \\
\hline Total patients in cyclosporin associations & $28(54)$ \\
\hline Graft kidney immediate functioning & $40(76)$ \\
\hline One acute rejection episode & $20(38)$ \\
\hline Two acute rejection crises & $4(7.7)$ \\
\hline Mean blood creatinine at 1 year & $\begin{array}{c}1.2 \pm 0.35 \mathrm{mg} / \mathrm{dL} \\
106.08 \pm 30.94 \\
\mathrm{mmol} / \mathrm{L}\end{array}$ \\
\hline Current mean blood creatinine & $1.3 \mathrm{mg} / \mathrm{dL}$ \\
\hline
\end{tabular}


and $>30$ years - with success similar to those receiving have a living donor allograft. One of the most important clinical determinants seems to be in every study a low cold ischemia time from donors, as well as younger age donors. We think that maintaining follow up in the same center all over the years is also a good determinant for good results (we only lost for follow up 17/408 patients and in Necker also 40/499. We can also conclude that CSA nephrotoxicity has low if any impact on long-term graft survival and can result in good graft function if used in adequate doses.

\section{REFERENCES}

[1] Cecka JM. Kidney transplantation in the United States. Clin Transpl 2008:1-18.
[2] Bererhi L, Pallet N, Zuber J, et al. Clinical and immunological features of very long-term survivors with a single renal transplant. Transpl Int 2012;25:545-54.

[3] Traynor C, Jenkinson A, Williams Y, et al. Twenty-year survivors of kidney transplantation. Am J Transplant 2012;12: 3289-95.

[4] El-Zoghby ZM, Stegall MD, Lager DJ, et al. Identifying specific causes of kidney allograft loss. Am J Transplant 2009;9: $527-35$.

[5] Gourishankar S, Leduc R, Connett J, et al. Pathological and clinical characterization of the 'troubled transplant': data from the DeKAF study. Am J Transplant 2010;10:324-30.

[6] Matas AJ. Chronic progressive calcineurin nephrotoxicity: an overstated concept. Am J Transplant 2011;11:687-92.

[7] Snanoudj R, Royal V, Elie C, et al. Specificity of histological markers of long-term CNI nephrotoxicity in kidney-transplant recipients under low-dose cyclosporine therapy. Am J Transplant 2011;11:2635-46. 